\title{
Effect of Bias Voltage and Nitrogen Pressure on the Structure and Properties of Vacuum-Arc (Mo + Ti6\% Si)N Coatings
}

\author{
V. M. Beresnev, O. V. Sobol', S. V. Litovchenko*, A. D. Pogrebnyak, P. A. Srebnyuk, \\ V. Yu. Novikov, D. A. Kolesnikov, A. A. Meilekhov, A. A. Postel'nik, and U. S. Nemchenko \\ Karazin National University, pl. Svobody 4, Kharkov, 61022 Ukraine \\ *e-mail: s.lytovchenko@karazin.ua \\ Received September 6, 2016
}

\begin{abstract}
Effect of deposition conditions in reactive nitrogen atmosphere on the growth morphology, phase composition, structure, and mechanical characteristics (microhardness) of vacuum-arc multilayer coatings obtained using evaporation of the $(\mathrm{Ti} 6 \% \mathrm{Si})$ and $\mathrm{Mo}$ cathodes is studied with the aid of raster electron microscopy, energy-dispersive elemental microanalysis, and microindentation. It is demonstrated that nitrogen atoms are redistributed to the region of the strongest nitride-forming element (Ti) in relatively thin layers (about $7 \mathrm{~nm}$ ) consisting of substances with substantially different heats of formation $(-336 \mathrm{~kJ} / \mathrm{mol}$ for TiN and $-34 \mathrm{~kJ} / \mathrm{mol}$ for MoN). Such a process leads to lamination with the formation of nitride TiN and metal Mo (weaker nitride-forming element). Nitrogen-metal bonds are saturated in the layers of strong nitrideforming elements $\mathrm{Ti}(\mathrm{Si})$ when the nitrogen pressure increases from $6 \times 10^{-4}$ to $5 \times 10^{-3}$ Torr in the condensation procedure. Thus, the compound is filled with nitrogen to the stoichiometric composition and, then, the second system of layers based on molybdenum is saturated with nitrogen with the formation of the $\gamma$ $\mathrm{Mo}_{2} \mathrm{~N}$ phase. An increase in bias potential $U_{\mathrm{SP}}$ from -100 to $-200 \mathrm{~V}$ stimulates mixing in thin layers with the formation of the ( $\mathrm{Ti}, \mathrm{Si}, \mathrm{Mo}) \mathrm{N}$ solid solution and leads to a decrease in microhardness from 37 to $32 \mathrm{GPa}$.
\end{abstract}

DOI: $10.1134 / \mathrm{S} 1063784217050073$

\section{INTRODUCTION}

Additional requirements on the surface properties of components and structures emerge due to the development of modern technologies. The desired functional properties can be reached using deposition of relatively thin (with a thickness of up to $10 \mu \mathrm{m}$ ) multielement coatings [1-3]. When the vacuum-arc technology is employed, the best (primarily, mechanical) properties are obtained for multielement coatings based on nitrides of transition metals [4-8].

Rapid recent progress in structural engineering is related to the study of the composition of multielement coatings, regularities of the formation of structure and stressed state, and the relation of the parameters and physicochemical characteristics [9-11]. The corresponding results are used to interpret physical processes of the formation of nanocrystalline solid coatings under strongly nonequilibrium conditions for deposition of vacuum-plasma fluxes [12-14]. In this regard, the method for formation of multilayer structures with nanosized periods is employed for efficient control of nanostructure state of coatings [15, 16]. Crystallite structures with variable structural nonequilibrium, imperfection, and element distribution in volume and interfacial regions are formed when the composite structures are fabricated [17-20].
The purpose of this work is the analysis of regularities of the formation of phase composition and structural state of multiplayer nanocomposite nitride condensates obtained with the aid of vacuum-arc evaporation of two ( $\mathrm{Ti}+\mathrm{Si}$ and $\mathrm{Mo}$ ) targets in nitrogen atmosphere and the study of the effect of the structural phase state of condensate on the mechanical properties of the composite. A multilayer condensate is obtained using substrate rotation in the course of deposition.

\section{EXPERIMENTAL SAMPLES AND METHODS}

The samples are fabricated with the aid of the vacuum-arc technology using an improved Bulat-6 setup [21]. The working pressure of nitrogen in the course of deposition is $(0.6-5) \times 10^{-3}$ Torr. For deposition of coatings, we use two $(\mathrm{Ti}+6 \% \mathrm{Si}$ and $\mathrm{Mo})$ sources and continuously rotate samples fixed on the substrates at a rate of $8 \mathrm{rpm}$. A time interval of $1 \mathrm{~h}$ is needed to obtain a sample with a thickness of $7 \mathrm{~nm}$ (960 layers or 480 bilayer periods). Silicon is preliminary introduced in the titanium target and is deposited in the coating at an amount of $0.8-1$ at $\%$ for enhancement of nitride formation in the TiN layers and the formation of the (TiSi) $\mathrm{N}$ composite. Constant bias voltage $U_{\mathrm{SP}}$ ranging 
(a)

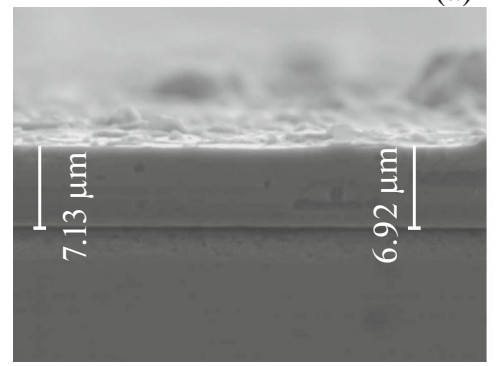

(b)

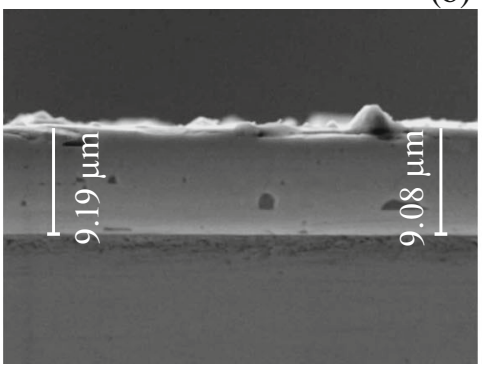

(c)

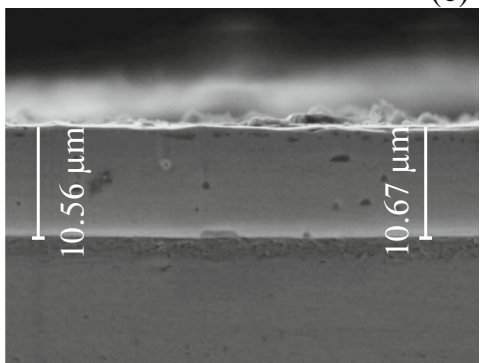

Fig. 1. Morphology of the cross sections of coatings fabricated at (a) $U_{\mathrm{SP}}=-200 \mathrm{~V}$ and $P_{\mathrm{N}}=6.0 \times 10^{-4}$ Torr, (b) $U_{\mathrm{SP}}=-200 \mathrm{~V}$ and $P_{\mathrm{N}}=5.0 \times 10^{-3}$ Torr, and (c) $U_{\mathrm{SP}}=-100 \mathrm{~V}$ and $P_{\mathrm{N}}=5.0 \times 10^{-3}$ Torr.
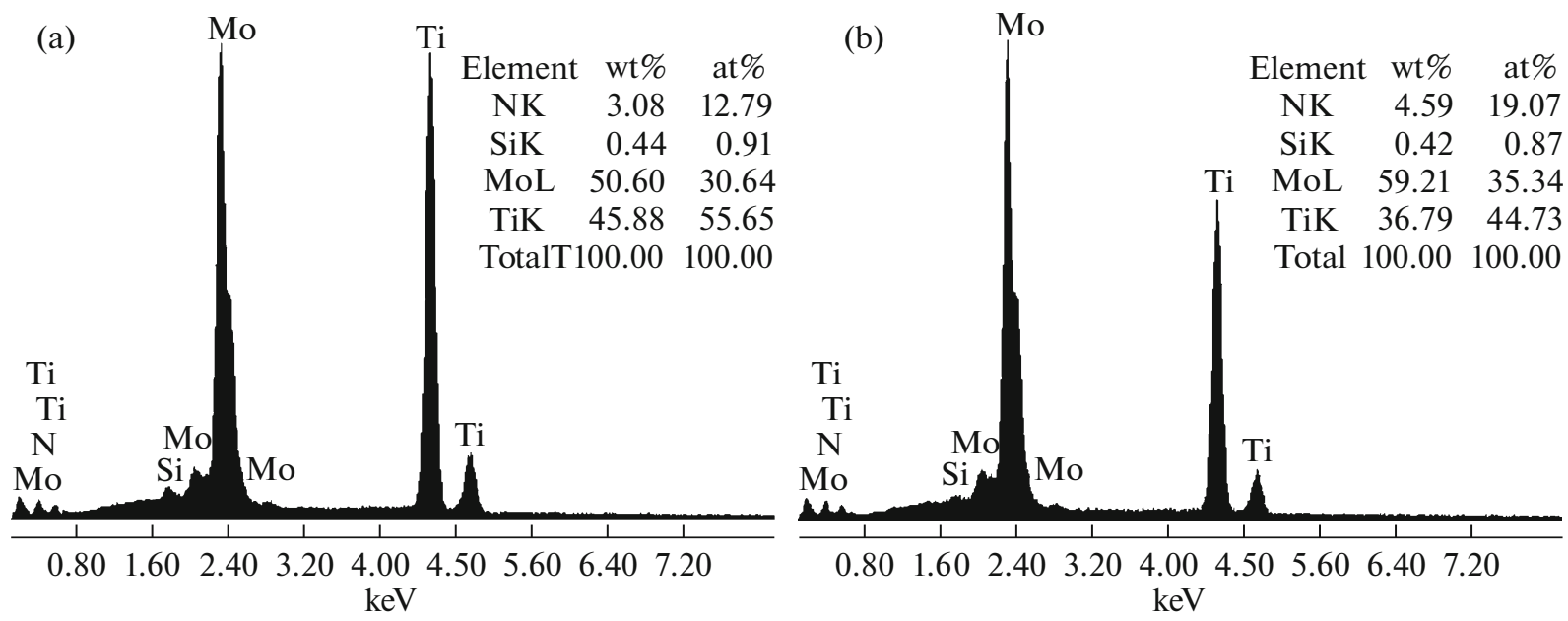

Fig. 2. Energy dispersive spectra and elemental composition of coatings obtained at $U_{\mathrm{SP}}=-100 \mathrm{~V}$ and $P_{\mathrm{N}}=\left(\right.$ a) $6.0 \times 10^{-4}$ and (b) $5.0 \times 10^{-3}$ Torr.

from -100 to $-200 \mathrm{~V}$ is applied to the substrates in the course of deposition.

A DRON-4 setup ( $\mathrm{Cu}-k_{\alpha}$ radiation) is employed for the structural phase analysis using the X-ray diffractometry. The components are determined with the aid of the NewProfile software (designed at National Technical University "Kharkov Polytechnical Institute"). The microhardness is measured using a DM-8 device at an indenter load of $50 \mathrm{~g}$.

To determine the elemental composition of coatings, we employ the spectra of characteristic X-ray radiation generated by electron beam in an FEI Nova NanoSEM 450 raster electron microscope. The spectra are measured using an EDAX PEGASUS energy dispersive X-ray spectrometer interfaced with the microscope.

\section{RESULTS AND DISCUSSION}

The analysis of the morphology of side cross sections of coatings obtained in the entire interval of working nitrogen pressures $P_{\mathrm{N}}$ at constant bias voltage of the substrate $U_{\mathrm{SP}}$ shows relatively high homogeneity and low content of defects over thickness (Fig. 1). A decrease in pressure $P_{\mathrm{N}}$ (Fig. 1a) and an increase in potential $U_{\mathrm{SP}}$ (Fig. 1b) in the deposition procedure lead to a decrease in the thickness of coating, presumably, due to stimulation of the processes of secondary sputtering [4]. The same processes provide variations in the elemental composition.

Analysis and generalization of the energy dispersive spectra (Figs. 2 and 3) indicate that relative enrichment of coatings with the strongest nitride-forming element $(\mathrm{Ti})$ takes place at the lowest nitrogen pressure. Under such conditions, the probability of atomic collisions in the interelectrode gap with a decrease in energy is relatively low and the rate of secondary sputtering is relatively high due to bombardment with high-energy particles $[4,11]$.

An increase in bias voltage $U_{\mathrm{SP}}$ from -100 to $-200 \mathrm{~V}$ stimulates the selective enrichment of coating with the Ti atoms (Fig. 3b). Note that the content of Si added for the enhancement of nitride formation in the coating is no greater than 1 at \% (ranges from 0.8 to 1 at \%). 

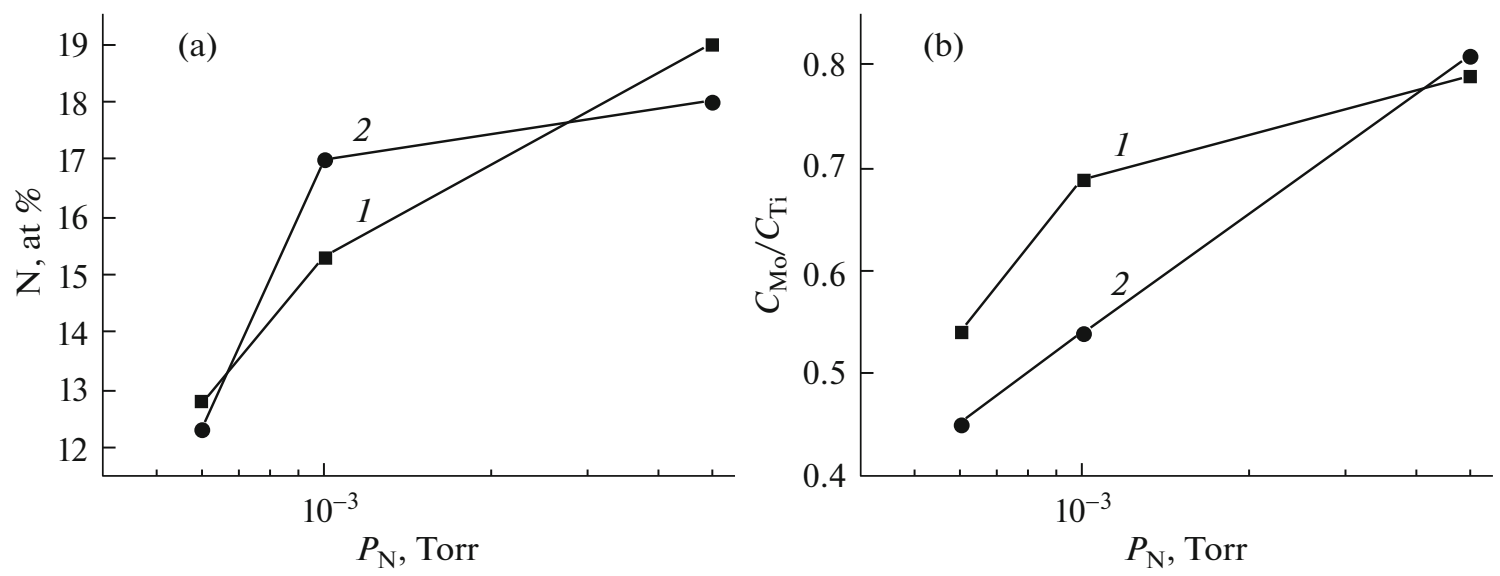

Fig. 3. Plots of (a) nitrogen content and (b) $C_{\mathrm{Mo}} / C_{\mathrm{Ti}}$ ratio vs. nitrogen pressure in the deposition procedure at $U_{\mathrm{SP}}=(1)-100$ and (2) $-200 \mathrm{~V}$.
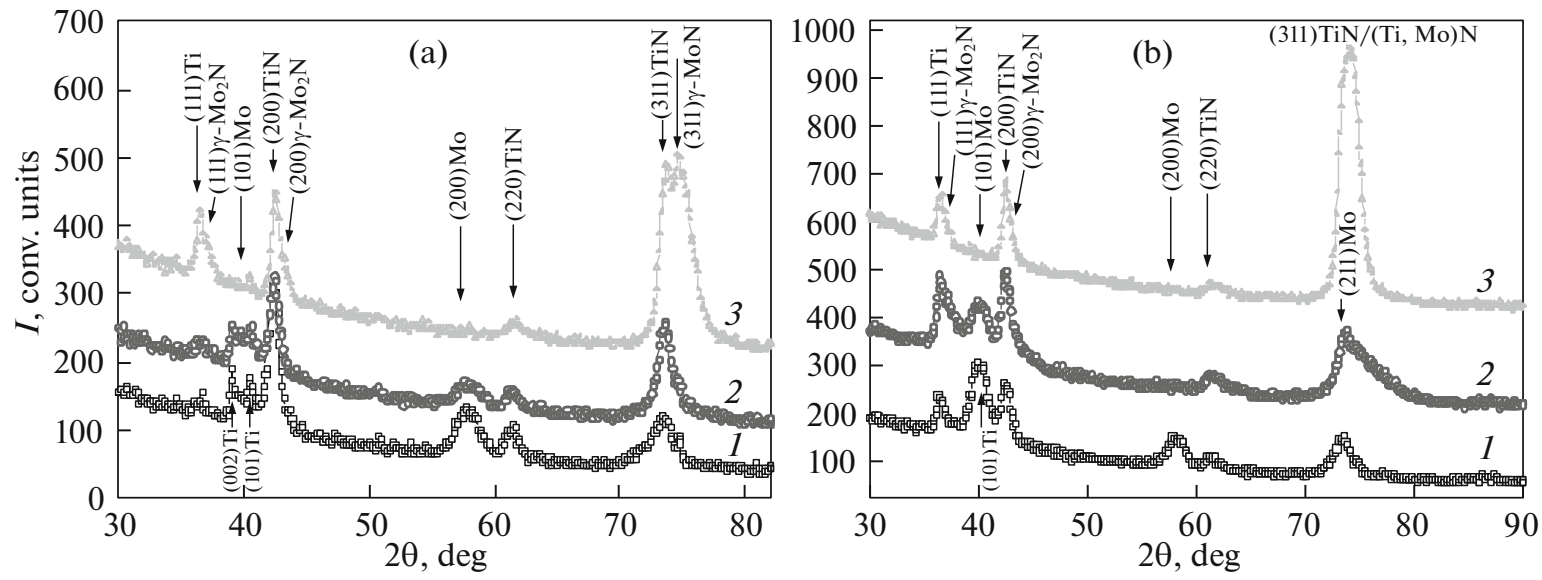

Fig. 4. Diffraction spectra of the coatings obtained at $P_{\mathrm{N}}=(1) 6.0 \times 10^{-4}$, (2) $1.0 \times 10^{-3}$, and (3) $5.0 \times 10^{-3}$ Torr and $U_{\mathrm{SP}}=(\mathrm{a})-100$ and (b) $-200 \mathrm{~V}$.

Lamination with the formation of the $\mathrm{SiN}_{x}$ phase was not expected at such Si content [1]. The X-ray analysis proves the assumption, since the peaks corresponding to the $\mathrm{SiN}_{x}$ phase are not detected on the diffraction spectra (Fig. 4).

As was expected, the minimum nitrogen content is obtained for the coating fabricated at the lowest pressure $\left(P_{\mathrm{N}}=6.0 \times 10^{-4}\right.$ Torr). The X-ray spectra (Fig. 4) show that nitrogen is primarily bound with the strong nitride-forming element (titanium) and silicon dissolved in it. Thus, $\mathrm{Ti}(\mathrm{Si}) \mathrm{N}$ nitride with the predominant orientation of crystallites with the [100] axis is formed. The spectra also show the presence of $\alpha-\mathrm{Ti}$ and Mo in which the nitrogen content is extremely low and the formation of nitride phases is impossible.

An increase in the nitrogen pressure in the deposition procedure causes an expected increase in the nitrogen content in the coatings (Fig. 3a). In addition, we observe an increase in the content of molybdenum, which is detected in the spectra as the isostructural (with respect to titanium nitride) phase $\gamma-\mathrm{Mo}_{2} \mathrm{~N}$ at the maximum pressure $\left(P_{\mathrm{N}}=5.0 \times 10^{-3}\right.$ Torr $)$.

The arm with the sample holder is rotated, so that the substrate continuously moves from one source to another [7]. Thin (about $7 \mathrm{~nm}$ ) condensate layers are formed in this case. A higher heat of formation of titanium nitride leads to the redistribution of the nitrogen atoms in the coating. At a low nitrogen pressure in the deposition procedure, nitrogen migrates from the Mo layers to the Ti layers. The process is stimulated in the presence of $\mathrm{Si}$ atoms in $\mathrm{Ti}$, so that $\mathrm{TiN}$ and Mo layers are formed in the film.

Both TiN and $\gamma-\mathrm{Mo}_{2} \mathrm{~N}$ nitrides are formed only at high nitrogen pressure $\left(5.0 \times 10^{-3}\right.$ Torr $)$ when the TiN phase is completely saturated with nitrogen.

A characteristic feature of the structural state of the above $\gamma-\mathrm{Mo}_{2} \mathrm{~N} / \mathrm{TiN}$ nitride coatings lies in the predominant formation of crystallites with the [311] axis 
perpendicular to the growth plane, which follows from a relative increase in the intensity of reflexes on spectra 3 (Fig. 3). The formation of such texture has been demonstrated only for the $\gamma-\mathrm{Mo}_{2} \mathrm{~N}$ coatings [11]. Thus, the structure of the $\gamma-\mathrm{Mo}_{2} \mathrm{~N}$ layers formed at a pressure of $P_{\mathrm{N}}=5.0 \times 10^{-3}$ Torr is the dominant structure with respect to the texture formation.

At the lower bias voltage $\left(U_{\mathrm{SP}}=-100 \mathrm{~V}\right)$, we observe the formation of two layers with different grating periods $(0.4258 \mathrm{~nm}$ for TiN and $0.4209 \mathrm{~nm}$ for $\gamma-\mathrm{Mo}_{2} \mathrm{~N}$ ). Diffraction spectrum 3 (Fig. 3a) exhibits two different reflexes at the corresponding positions. At the higher bias voltage $\left(U_{\mathrm{SP}}=-200 \mathrm{~V}\right)$, the [311] texture is sustained and a single peak with the position corresponding to a grating period of $0.4232 \mathrm{~nm}$ is observed. Apparently, the peak is related to the formation of the (Ti, Mo) N solid solution due to the radiation-stimulated mixing of atoms under the highenergy ion irradiation of the growing coating.

The analysis of the effect of the elemental structural state of coating on hardness as the most universal characteristic of mechanical properties shows that the formation of mixed layers at the higher potential $\left(U_{\mathrm{SP}}=-200 \mathrm{~V}\right)$ leads to a decrease in the hardness of coatings to a level of 32-33 GPa. Under otherwise equal conditions, the layer formation at the lower potential $\left(U_{\mathrm{SP}}=-100 \mathrm{~V}\right)$ makes it possible to increase the hardness to $37.3 \mathrm{GPa}$.

\section{CONCLUSIONS}

When multilayer coatings with thin $(7 \mathrm{~nm})$ layers are formed, relatively high mobility of light nitrogen atoms in the course of deposition leads to their directional migration to regions containing strong nitrideforming elements and the formation of the nitride/metal compositions.

An increase in the pressure of the working nitrogen atmosphere in the deposition procedure stimulates the saturation of the nitrogen-metal bonds in the layers with strong nitride-forming elements $\mathrm{Ti}(\mathrm{Si})$. First, titanium nitride is filled with nitrogen to the stoichiometric composition, and, then, the second system of layers (molybdenum films) is saturated with nitrogen with the formation of the $\gamma-\mathrm{Mo}_{2} \mathrm{~N}$ phase.

An increase in bias voltage $U_{\mathrm{SP}}$ from -100 to $-200 \mathrm{~V}$ stimulates mixing processes with the formation of the ( $\mathrm{Ti}, \mathrm{Si}, \mathrm{Mo}) \mathrm{N}$ solid solution and leads to a decrease in hardness from 37 to $32 \mathrm{GPa}$.

\section{REFERENCES}

1. Nanostructured Coatings, Ed. by A. Cavaleiro and J. Th. M. de Hosson (Springer, New York, 2006).

2. A. D. Pogrebnyak, A. A. Drobyshevskaya, V. M. Beresnev, M. K. Kylyshkanov, E. V. Kirik, S. N. Dub, F. F. Komarov, A. P. Shipilenko, and Yu. Zh. Tuleushev, Tech. Phys. 56, 1023 (2011).

3. O. V. Sobol', O. N. Grigorjev, Yu. A. Kunitsky, S. N. Dub, A. A. Podtelezhnikov, and A. N. Stetsenko, Sci. Sintering 38, 63 (2006).

4. O. V. Sobol', A. A. Andreev, V. A. Stolbovoi, and V. E. Fil'chikov, Tech. Phys. Lett. 38, 168 (2012).

5. W. D. Munz, J. Vac. Sci. Technol., A 4, 2717 (1986).

6. A. D. Pogrebnyak, A. P. Shpak, N. A. Azarenkov, and V. M. Beresnev, Phys. Usp. 52, 29 (2009).

7. V. M. Beresnev, O. V. Sobol, I. N. Toryanik, A. A. Meylekhov, U. S. Nyemchenko, P. V. Turbin, I. V. Yakushchenko, and M. O. Lisovenko, J. Nano-Electron. Phys. 6, 01030 (2014).

8. M. Hua, H. Y. Maa, J. Li, and C. K. Mok, Surf. Coat. Technol. 200, 3612 (2006).

9. O. V. Sobol', Phys. Solid State 49, 1161 (2007).

10. P. I. Ignatenko, Tech. Phys. 56, 264 (2011).

11. O. V. Sobol', Phys. Met. Metallogr. 91, 60 (2001).

12. O. Knotek, M. Bohmer, T. Leyendecker, and F. Jungblut, Mater. Sci. Eng. A 105-106, 481 (1988).

13. O. V. Sobol', A. A. Andreev, S. N. Grigoriev, V. F. Gorban', S. N. Volosova, S. V. Aleshin, and V. A. Stolbovoy, Probl. At. Sci. Technol., No. 4, 174 (2011).

14. R. A. Andrievskii, "Synthesis and properties of interstitial phase films," Usp. Khim. 66 (1), 57 (1997).

15. O. V. Sobol', A. A. Andreev, V. F. Gorban', V. A. Stolbovoi, A. A. Meilekhov, and A. A. Postel'nik, Tech. Phys. 61, 1060 (2016).

16. G. Hakansson, J. E. Sundgren, D. Mcintyre, J. E. Greene, and W. D. Munz, Thin Solid Films 153, 55 (1987).

17. Metastable, Mechanically Alloyed and Nanocrystalline Materials, Ed. by R. Shulz (Transtech, Zurich, 1996), Part 1.

18. H. M. Benia, M. Guemmaz, G. Schmerber, A. Mosser, and J.-C. Parlebas, Appl. Surf. Sci. 200, 231 (2002).

19. S. Heinrich, S. Schirmer, D. Hirsch, J. W. Gerlach, D. Manova, W. Assmann, and S. Mändl, Surf. Coat. Technol. 202, 2310 (2008).

20. P. H. Mayrhofer, Ch. Mitterer, J. G. Wen, J. E. Greene, and I. Petrov, Appl. Phys. Lett. 86, 131909 (2005).

21. I. I. Aksenov, A. A. Andreev, V. A. Belous, V. E. Strel'nitskii, and V. M. Khoroshikh, Vacuum Arc: Plasma Sources, Coating Deposition, Surface Modification (Naukova Dumka, Kiev, 2012).

Translated by A. Chikishev

Effect of Bias Voltage and Nitrogen Pressure on the Structure and Properties o

f Vacuum-Arc (Mo + Ti6\% $\%$ Si)N Coatings [Текст] /

V.M. Beresnev, O.V. Sobol', S.V. Litovchenko [та ін.] // Technical Physics. — 2017. — №62(5). — C. $795-798$. 